\title{
DOENÇA DE CHAGAS: os 100 anos da descoberta e a atualidade do pensamento do seu descobridor
}

DESCRITORES - Doença de Chagas, história. Chagas, Carlos. Biografia.

Comemoramos neste ano o centenário da publicação da descoberta da doença de Chagas. Seu descobridor foi o eminente médico e cientista brasileiro Carlos Chagas, nascido em 1879. Chagas graduou-se na Faculdade de Medicina no Rio de Janeiro em 1903 e trabalhou com Oswaldo Cruz no Instituto de Manguinhos, RJ. Em seguida, como sanitarista e pesquisador, trabalhou para a erradicação da malária em Santos, SP. Em 1908, Chagas mudou-se para a cidade de Lassance, no interior de Minas Gerais, por ocasião da expansão das malhas férreas. Lá ele clinicava no apoio à melhoria das condições de saúde de trabalhadores, em situação de alta mortalidade por moléstias tropicais, principalmente a malária e a febre amarela ${ }^{(13)}$.

Nesta atividade, Chagas conheceu os insetos que cohabitavam as moradias da população humilde e que sugavam seu sangue à noite, conhecidos por "barbeiros". Naquele mesmo ano, detectou a presença de novos protozoários no intestino dos "barbeiros" e formulou a hipótese de que estivessem relacionados à doença misteriosa que afligia a população da região, com sintomas diversos, predominantemente cardíacos. Finalmente, em 1909, ele examinou uma criança, chamada Berenice, que apresentava febre, edemas e ingurgitação linfática generalizada. No seu sangue encontrou os protozoários que observara no intestino de "barbeiros" no ano anterior, descobrindo, assim, uma nova doença, que denominou Tripanosomíase americana. Em agosto de 1909, Chagas publicou, no primeiro volume das Memórias do Instituto Oswaldo Cruz, um extenso e muito bem redigido artigo, onde relata a morfologia e o ciclo de vida do tripanosoma ${ }^{(13)}$.

Caso único na história da medicina, Chagas descreveu, na mesma doença, o agente etiológico, o vetor, as manifestações clínicas das fases aguda e crônica, o reservatório na natureza (animais selvagens), vários aspectos da patogenia e inferiu o seu impacto socioeconômico ${ }^{(15)}$. Recebeu muitas críticas agressivas e invejosas pelo seu trabalho, mas também vários prêmios, títulos honoris causa e homenagens nacionais e internacionais, vindo a falecer em 1934, no Rio de Janeiro, aos 56 anos de idade.

\section{A DOENÇA DE CHAGAS 100 ANOS DEPOIS DA DESCOBERTA}

Ao longo desses 100 anos, desde a descoberta da doença de Chagas, constatou-se que a paciente Berenice não teve a forma crônica da doença, tendo falecido aos 72 anos de idade, vítima de um acidente vascular cerebral. Um século após a descoberta da doença, a população de Lassance continua a viver em condições bastante precárias e ainda há barbeiros em muitas residências na região ${ }^{(11)}$. É interessante notar que em 1911, Chagas já sugeria a melhoria das casas como meio de eliminação do vetor. Um século depois, a doença ainda é uma tragédia silenciosa que atinge milhões de pessoas na América Latina ${ }^{(21)}$. Em 2006, o Brasil foi considerado pela Organização Pan Americana de Saúde como o primeiro país latino-americano a interromper a transmissão da doença via vetor, embora esporadicamente novos casos sejam relatados, inclusive de transmissão por alimentos. Hoje estima-se que por volta de 16 milhões de pessoas estejam infectadas pelo Trypanosoma cruzi e cerca de 75 a 90 milhões estejam sob potencial risco de se tornarem infectadas ${ }^{(5)}$. Embora originária da América Latina, muitos casos da doença ocorrem em outros continentes por conta da migração de indivíduos.

\section{ALGUNS ASPECTOS HISTÓRICOS E ATUAIS DA FORMA DIGESTIVA DA DOENÇA DE CHAGAS}

Sabe-se, há muito tempo, da alta prevalência de disfagia no interior do Brasil. No livro Brazil and Brazilians (1857), dois missionários americanos, Kidder e Fletcher, já descreviam o "mal de engasgo" como uma nova doença no Brasil. A partir do início do século XX, várias hipóteses foram formuladas para explicar o mal, como por exemplo, Paranhos, que em 1913, propôs a existência de uma toxina na farinha de mandioca; Parisi que propôs uma forma de malária (1925) e Etzel, que propôs o papel de desnutrição, particularmente o da avitaminose $\mathrm{B} 1^{(17,18)}$.

É interesssante que o próprio Carlos Chagas já havia proposto, em $1916^{(3,4)}$, o papel da infecção pelo 
Trypanosoma cruzi na gênese da doença, o que foi desconsiderado pelos meios médicos e científicos no período, até a década de 1950. É muito provável que isto tenha relação com a forte oposição que Chagas encontrou à época na Academia Nacional de Medicina, fazendo com que a doença por ele descrita ficasse no esquecimento por cerca de $20 \operatorname{anos}^{(22)}$. Nessa mesma época, Chagas foi indicado para o prêmio Nobel em duas ocasiões. Admite-se que, ao menos em 1921, quando por motivos pouco claros ninguém foi nomeado para o prêmio e a não premiação do genial cientista possa ter ocorrido em razão da forte oposição que enfrentou no Brasil por parte de alguns médicos e pesquisadores da época, que chegaram mesmo a questionar a existência da doença de Chagas, influenciando a decisão do Comitê Nobel para não premiá-lo ${ }^{(2)}$. Por outro lado, há quem conteste que esta oposição a Carlos Chagas, embora profundamente lamentável, tenha sido decisiva quanto à não premiação em 1921 porque outros fatores poderiam ter influenciado as decisões do Comitê Nobel ${ }^{(16)}$.

$\mathrm{Na}$ década de 30, diversos clínicos do interior do Brasil passaram a defender a idéia de que o megacólon e o megaesôfago tivessem causa chagásica ${ }^{(15)}$. Isto se confirmou em diversos trabalhos, destacando-se os de ETZEL $^{(7)}$ e o de AMORIM e CORREA-NETO ${ }^{(1)}$, os quais demonstravam ser o megaesôfago e o megacólon uma mesma doença, cujo achado histopatológico mais característico consiste na degeneração do plexo mientérico, encontrada em todo o trato digestório, e não apenas nos segmentos dilatados. Alguns autores, dentre os quais destaca-se FREITAS ${ }^{(8)}$, demonstram com dados clínicos, epidemiológicos e sorológicos a relação etiológica entre a doença de Chagas e o megaesôfago e o megacólon endêmicos. $\mathrm{Na}$ realidade, a referência mais antiga a este respeito já data de 1922 e deve-se a Chagas e Villela que encontraram quatro casos de megaesôfago em 63 pacientes chagásicos ${ }^{(18)}$.

O conceito de que as dilatações de vísceras fossem secundárias à desnervação intrínseca das mesmas foi enfatizado no período de 1952 a 1970 pelo Prof. Fritz Koberle, patologista austríaco radicado na Faculdade de Medicina de Ribeirão Preto da Universidade de São Paulo(18). Este pesquisador realizou pesquisas baseadas em estudos histopatológicos detalhados, que culminaram na formulação da sua Teoria neurogênica para a fisiopatologia das formas cardíaca e digestiva da doença de Chagas. Nesses estudos foram feitas correlações entre as populações de neurônios dos plexos submucosos e mientéricos com as megavísceras chagásicas, principalmente megaesôfago e megacólon. Foram estudos exaustivos, nos quais mais de 350 mil neurônios foram contados! Constatouse cabalmente que a desnervação intrínseca de vísceras ocas era componente essencial da patogênese das dilatações.

Novamente aqui se deve fazer justiça à genialidade de Chagas, que já havia descrito a lesão de células nervosas viscerais associada à tripanossomíase ${ }^{(4)}$. Fazia parte também da Teoria neurogênica a hipótese de que a maior parte da perda neuronal ocorresse na fase aguda da doença, motivo pelo qual Koberle propunha que o destino do chagásico era "selado na fase aguda da doença" (14). Como logo se observou que muito raramente se encontravam neurônios parasitados, Koberle também propôs a existência de uma hipotética neurotoxina produzida pelos tripanossomos, que lesaria seletivamente as células nervosas. Entretanto, nem Koberle ou qualquer outro pesquisador da época conseguiram demonstrar a existência de tal neurotoxina. Outros problemas em relação à Teoria neurogênica foram a observação por diversos autores de fenômenos de autoimunidade e também a ocorrência de perda contínua de neurônios, ou seja, a desnervação não se restringia à fase aguda da doença ${ }^{(17)}$. Somente 43 anos depois da elaboração da Teoria neurogênica é que foi possível se demonstrar a existência de uma substância, associada à infecção chagásica, que lesaria os neurônios intramurais do tubo digestório. Não se trata de uma toxina propriamente dita, mas de óxido nítrico - e possivelmente outros radicais livres - liberado na reação inflamatória periganglionar. Este agente, componente da defesa contra o microorganismo, afeta colateralmente os neurônios vizinhos à reação inflamatória e o seu bloqueio farmacológico reduz acentuadamente as lesões neuronais ${ }^{(9)}$. Ainda aqui, há que se fazer justiça à genialidade de Carlos Chagas. A releitura cuidadosa de seus textos mostra que, na verdade, estes mecanismos não escaparam da observação acurada e da interpretação brilhante daquele pesquisador, quando afirmou que também eram lesadas as células não parasitadas que circundavam aquelas infectadas e ao tecido inflamado ${ }^{(4)}$. Refletimos aqui que, embora seja muito difícil de definir o que seria genialidade, certamente este conceito passa pela capacidade de se ver o que os demais não estão vendo e de se antever os rumos dos acontecimentos além do seu tempo, atributos estes que certamente não faltavam a Carlos Chagas.

Sabe-se hoje também que as lesões neuronais não ocorrem ao acaso, mas que existe algum tipo de seletividade para subpopulações distintas de neurônios, como ilustra, por exemplo, o fato de que a inervação excitatória é mais intensamente lesada no megaesôfago chagásico do que na acalásia idiopática $^{(6)}$. Recentemente, uma sequência de trabalhos, bem conduzidos e cientificamente embasados, alguns deles elaborados por pesquisadores brasileiros em parceria com o eminente Prof. John Furness, da Austrália, trouxe novas contribuições ao entendimento da fisiopatologia da forma digestiva da doença de Chagas. Ficou bem estabelecido que a imunidade e a inflamação crônica persistente têm papel importante na evolução do megaesôfago e que fenômenos de neuroplasticidade fazem parte da fisiopatologia da doença ${ }^{(19,20)}$. Outra linha de pesquisa que se abriu nas últimas duas décadas foi a do estudo da relação entre megaesôfago e aumento de risco de câncer e da redução de incidência desta doença no megacólon ${ }^{(10,12)}$. A partir desses estudos, novas informações têm surgido e contribuído para a melhor compreensão da carcinogênese do tubo digestivo e quiçá, contribuirão também para que se desenhem novas estratégias preventivas ao câncer.

Concluímos lembrando que, além de seu magnífico trabalho como médico, pesquisador e administrador, Chagas era também um grande professor, que afirmava sua convicção da conveniência de sempre se "pesquisar ensinando e ensinar pesquisando". Nesta frase simples ilustra-se um pensamento inspirador que ajudou a 
moldar toda uma geração de pesquisadores brasileiros e que continua válido nos dias de hoje para aqueles que trabalham na formação das novas gerações de pesquisadores. Terminamos, portanto, aliando-nos com ardor a todas as justas homenagens que neste ano têm sido prestadas ao grande mestre: Carlos Chagas.

\section{Sérgio Britto GARCIA*}

Garcia SB. Chagas' disease: 100 years of discovery and current thought of its discoverer. Arq Gastroenterol. 2009;46(4):249-51.

HEADINGS - Chagas disease, history. Chagas, Carlos. Biography.

\section{REFERÊNCIAS}

1. Amorim M, Correa-Neto A. Histopathologia e pathogenese do megaesôfago e megareto. Considerações em torno de um caso de "mal do engasgo". Ann Fac Med Univ São Paulo. 1932;8:101-27.

2. Bestetti RB, Martins CA, Cardinalli-Neto A. Justice where justice is due: a posthumous Nobel Prize to Carlos Chagas (1879-1934), the discoverer of American Trypanosomiasis (Chagas' disease). Int J Cardiol. 2009;134:9-16.

3. Chagas C. Tripanosomiase americana; forma aguda da doença. Mem Inst Oswaldo Cruz. 1916;8:37-60.

4. Chagas C. Processos patojenicos da tripanozomiase americana. Mem Inst Oswaldo Cruz. 1916;8:5-36.

5. Coura JR, Dias JC. Epidemiology, control and surveillance of Chagas disease: 100 years after its discovery. Mem Inst Oswaldo Cruz. 2009;104(suppl 1):31-40.

6. Dantas RO. Comparison between idiopathic achalasia and achalasia caused by Chagas' disease: a review about the pathophysiology of the diseases. Arq Gastroenterol. 2003;40:126-30.

7. Etzel E. Neuropatologia do megaesôfago e megacolo. Estudo de 5 casos. Ann Fac Med Univ São Paulo. 1934;10:383-95.

8. Freitas JLP. Contribuição para o estudo do diagnóstico da moléstia de Chagas por processos de laboratório [tese]. São Paulo: Faculdade de Medicina da Universidade de São Paulo; 1947.

9. Garcia SB, Paula JS, Giovannetti GS, Zenha F, Ramalho EM, Zucoloto S, Silva JS, Cunha FQ. Nitric oxide is involved in the lesions of the peripheral autonomic neurons observed in the acute phase of experimental Trypanosoma cruzi infection. Exp Parasitol. 1999;93:191-7.

10. Garcia SB, Aranha AL, Garcia FR, Basile FV, Pinto AP, de Oliveira EC, Zucoloto S. A retrospective study of histopathological findings in 894 cases of megacolon: what is the relationship between megacolon and colonic cancer? Rev Inst Med Trop São Paulo. 2003;45:91-3.
11. Geraque E. Doença de Chagas completa 100 anos e persiste no local da descoberta. Folha de São Paulo, 12/04/2009.

12. Lopes ER - Megaesophagus, megacolon and cancer. Rev Soc Bras Med Trop 1988, 21:91-94

13. Morel CM. Chagas disease, from discovery to control - and beyond: history, myths and lessons to take home. Mem Inst Oswaldo Cruz. 1999;94(suppl 1):3-16

14. Oliveira JSM, Koberle F. Vinte e cinco anos da teoria neurogênica. In: Modernos conhecimentos sobre doença de Chagas. Belo Horizonte: Universidade Federal de Minas Gerais; 1981

15. Prata A. Evolution of the clinical and epidemiological knowledge about Chagas disease 90 years after its discovery. Mem Inst Oswaldo Cruz. 1999;94(suppl 1):81-8.

16. Pitella JEH. O processo de avaliação em ciência e a indicação de Carlos Chagas ao prêmio Nobel de fisiologia ou medicina. Rev Soc Bras Med Tropical. 2009;42:67-72.

17. Rezende JM. The digestive tract in Chagas' disease. Mem Inst Oswaldo Cruz. 1984;79:97-106.

18. Rezende JM. A viagem científica de Neiva e Penna: roteiro para os estudos das doenças do sertão. Hist Ciênc Saúde-Manguinhos. 2009;16(supl 1):265-88.

19. Silveira AB, Arantes RM, Vago AR, Lemos EM, Adad SJ, Correa-Oliveira R, D'Avila-Reis D. Comparative study of the presence of Trypanosoma cruzi kDNA, inflammation and denervation in chagasic patients with and without megaesophagus. Parasitology. 2005;131:627-34.

20. Silveira AB, Freitas MA, de Oliveira EC, Neto SG, Luquetti AO, Furness JB Correa-Oliveira R, d'Avila Reis D. Neuronal plasticity of the enteric nervous system is correlated with chagasic megacolon development. Parasitology. 2008; $135: 1337-42$

21. Souza DO. Doença de Chagas: é hora de romper o silêncio. Folha de São Paulo, 09/07/2009.

22. Wendel S, Brener Z. Historical aspects, p. 5-12. In: Wendel S, Brener Z, Camargo ME, Rassi, editors. Chagas disease (american trypanosomiasis): its impact on transfusion and clinical medicine. Rio de Janeiro: Sociedade Brasileira de Hematologia e Hemoterapia; 1992. p.5-12

* Departamento de Patologia e Medicina Legal, Faculdade de Medicina de Ribeirão Preto, Universidade de São Paulo, Ribeirão Preto, SP. 